\title{
Survival, growth and vulnerability to drought in fire refuges: implications for the persistence of a fire-sensitive conifer in northern Patagonia
}

\author{
Jennifer B. Landesmann ${ }^{1} \cdot$ Juan H. Gowda ${ }^{1} \cdot$ Lucas A. Garibaldi $^{2}$. \\ Thomas Kitzberger ${ }^{1}$
}

Received: 10 December 2014 / Accepted: 16 August 2015

(C) Springer-Verlag Berlin Heidelberg 2015

\begin{abstract}
Fire severity and extent are expected to increase in many regions worldwide due to climate change. Therefore, it is crucial to assess the relative importance of deterministic vs. stochastic factors producing remnant vegetation to understand their function in the persistence of fire-sensitive plants. Vegetation remnants (areas within the landscape that have not burned for a considerable amount of time) may occur stochastically or in more predictable locations (fire refuges) where physical conditions decrease fire severity. Our aim was to determine if remnant forests of the fire-sensitive conifer Austrocedrus chilensis are associated with biophysical attributes that allow persistence in a fire-prone Patagonian landscape. We conducted a multiscale approach, determining attributes of forest remnants and their surroundings (matrices) through remote sensing and field-based biophysical and functional characteristics, and quantifying how tree survival probability relates to microsite conditions. Trees within remnants displayed abundant fire scars, were twofold older and had threefold larger growth rates than matrix trees. Remnants were associated with high rocky cover and elevated topographical
\end{abstract}

Communicated by Jeremy Lichstein.

Electronic supplementary material The online version of this article (doi:10.1007/s00442-015-3431-2) contains supplementary material, which is available to authorized users.

Jennifer B. Landesmann

jennifer.landesmann@gmail.com

1 Laboratorio Ecotono, INIBIOMA-CONICET, Universidad Nacional del Comahue, Quintral 1250, CP 8400 Bariloche, Río Negro, Argentina

2 Sede Andina, Universidad Nacional de Río Negro (UNRN), CONICET, Mitre 630, CP 8400 Bariloche, Río Negro, Argentina positions. Tree survival increased in hilltops, eastern aspects, and with sparse vegetation. Trees within remnants experienced severe reductions in growth during droughts. Our results suggest that $A$. chilensis remnants are mainly the result of refuges, where environmental conditions increase fire survival, but also increase susceptibility to drought. A trade-off between fire survival and drought vulnerability may imply that under increasing drought and fire severity, locations that in the past have served as refuges may reduce their ability to allow the persistence of fire-sensitive taxa.

Keywords Basal area increment · Forest remnant . Climate change $\cdot$ Biophysical attributes $\cdot$ Austrocedrus chilensis

\section{Introduction}

Global warming is expected to largely affect forested landscapes through its amplifying effect on wildfire regimes. Rising global temperatures and increased fuel-drying conditions are expected to inevitably increase the size and severity of forest wildfires in many ecosystems worldwide (IPCC 2007; Flannigan et al. 2009). In addition, anthropogenic changes in ignition rates can produce rapid and often catastrophic shifts in the vegetation of certain biomes. Therefore, it is of paramount importance to understand the factors that govern the resilience of landscapes to altered fire regimes.

Landscape resilience depends on some form of ecological memory or legacy that buffers against disturbances, allowing for species persistence and ensuring the renewal of the landscape (Turner et al. 1998; Elmqvist et al. 2001). One of the main components of ecological memory is 
vegetation remnants which persist relatively unaffected by the disturbance and act as sources for dispersal and recolonization (Bengtsson et al. 2003). In the case of wildfires, remnant vegetation can be produced as a consequence of stochastic fire behavior, e.g., due to wind changes during the event (Bessie and Johnson 1995), or due to deterministic attributes. Therefore, remnants may be ephemeral and shift in location within the landscape, or they may be more permanent "fire refuges", i.e., fixed locations where physical conditions decrease fire severity, allowing the persistence of fire-sensitive forest taxa or communities (Camp et al. 1997; Wood et al. 2011; Mackey et al. 2012; Robinson et al. 2013; Leonard et al. 2014). Refuges may result from reduced fuel loads (e.g., in rocky outcrops), reduced flammability due to increased fuel moisture in cool-wet topographic positions, or reduced fire spread because of specific topographical configurations (Clarke 2002b; Wood et al. 2011; Mackey et al. 2012). In some systems, remnant patches (whether stochastically or deterministically produced) may become even more persistent in the landscape if these areas become less flammable than their surroundings as they age (Kitzberger et al. 2012). This can happen for instance if trees reach large diameters and develop thick bark (Ordóñez et al. 2005; Lawes et al. 2011), if the understories attain higher humidity (Uhl and Kauffman 1990), or if trees produce abundant litter or allelopathic substances that inhibit understory development, thus reducing flammability (van Wilgen et al. 1990).

Fire refuges play a key role for fire-sensitive forest taxa (long-lived, slow-growing, non-resprouting woody plants without a persistent seed bank), because they allow individuals to survive several fire events and subsequently function as seed sources (Ordóñez et al. 2005). For example, fire refuges have been documented for the fire-sensitive tree species Abies grandis and Abies concolor in the Wenatchee Mountain Range, a region with a long history of fire (Camp et al. 1997), and Pinus sabiniana in central and northern California (Schwilk and Keeley 2006). Furthermore, fire refuges may also provide habitat for wildlife (Robinson et al. 2013, 2014), sustain floristic diversity (Clarke 2002a, b) and maintain ecosystem functions. Most studies on forest fire refuges have focused on the description of their biophysical attributes, such as topography, age and size of trees (Camp et al. 1997; Perera et al. 2009; Román-Cuesta et al. 2009; De Long and Kessler 2000; Wood et al. 2011), but to our knowledge, no studies have assessed the probability of individual trees surviving fire events in relation to microsite conditions within remnants.

Despite their influence on landscape dynamics, fire refuges have received little attention worldwide and particularly in the southern temperate forests (but see Newton et al. 2011). Northern Patagonian forests (Argentina) have experienced recurrent natural and anthropogenic fires in relation to climatic variability (Veblen et al. 2008). In the late nineteenth century the frequency and extent of fires increased dramatically, primarily due to the use of fire by European settlers for opening farmland (Veblen et al. 2003). Consequently, forests dominated by relatively fire-sensitive and obligate seeder trees experienced a marked retraction of their ranges, while shrublands increased in extension (Veblen et al. 2003). This is because the former reproduce only from seed and thus the recolonization is slow, whereas the latter reproduce vegetatively, thus resprouting and recovering quickly after fire. Yet, forests have rapidly re-expanded over large areas of northern Patagonia during the last century, but mainly between 1914 and 1973 (Veblen and Lorenz 1988; Kitzberger and Veblen 1999; Gowda et al. 2012). Particularly intriguing is how the conifer Austrocedrus chilensis (D. Don) Pic. Serm. and Bizarri (Cupressaceae), could have persisted through such a fire-active period (1850-1900) (Veblen et al. 2003). This is striking if we consider its relative high fire sensitivity, the fact that it relies exclusively on seed reproduction, and the high severity and extent of late nineteenth century fires. In view of its limited dispersal capacity, the current expansion of A. chilensis forests can only be explained by invoking the persistence of small forest remnants spread out across the landscape (Kitzberger and Veblen 1999) that served as seed sources for forest recolonization associated with almost a century of active fire suppression (Mermoz et al. 2005; Gowda et al. 2012). Even though a few studies have documented the existence of old A. chilensis forest remnants in rocky outcrops (Willis 1914; Veblen and Lorenz 1988; Kitzberger and Veblen 1999), the mechanisms that have given regional fire persistence to this species are still unknown. Given the projected regional increase in the severity of extensive wildfires (Veblen et al. 2008) and the fact that $A$. chilensis is a near-threatened species (Souto and Gardner 2013), it is extremely important to determine the mechanisms that have allowed the species to persist throughout historical periods of high fire frequency.

Our study contributes to an understanding of the ecological functioning of fire refuges, i.e., their buffering capacity for fire-sensitive tree species which inhabit fire-prone landscapes. It is necessary to understand the way in which refuges exert protection and assess their resilience capability against fires which eventually influences the course of ecological succession (Keppel and Wardell-Johnson 2012; Robinson et al. 2013). Therefore, the aim of our work was to use A. chilensis remnant forests as a model system to determine if these are deterministic fire refuges and to identify biophysical attributes which allow trees to survive fire. Our main questions were: 
1. Are A. chilensis forest remnants the product of fixed fire refuges, or alternatively do these remnants survive fire due to stochastic factors?

2. If the remnants are deterministic refuges, how are they biophysically and functionally distinct from the surrounding landscape?

3. What microsite conditions within remnants allow individual trees or clusters of trees to survive fire?

We hypothesized that $A$. chilensis forest remnants (hereafter referred to as "forest remnant") are deterministic fire refuges that differ from their immediate surroundings (hereafter referred to as "matrix") in their biophysical and functional attributes, which enabled trees to survive fire. We further proposed that the mechanisms that allow forest remnants to survive fire may be functioning at different scales (landscape scale, local scale and clusters of trees or isolated trees within forest remnants). We expected that forest remnants would present attributes or signs of low productivity (and thus low fuel loads and low fire severity) compared to the matrix, with a high rock to vegetation ratio and elevated topographical positions in landscape. Similarly, we predicted that isolated trees or clusters of trees growing surrounded by rocks and located on steep slopes (and thus high fire velocity and lower fire severity) within the forest remnants would have a higher probability of surviving fires. We performed a multi-scale approach, first determining attributes of forest remnants and matrices through remote sensing, then assessing the biophysical and functional characteristics of forest remnants and matrices in the field and finally determining which of these attributes may explain the survival of clusters of trees and isolated trees to fire.

\section{Materials and methods}

\section{Study area and design}

The study was conducted in the central area of the Nahuel Huapi National Park, in northwestern Patagonia, Argentina (40-42 ${ }^{\circ} \mathrm{S}$ latitude), an area historically affected by several large fires (see Online Resource 1 for further details). We focused on areas with different fire history: one affected by fires between 1880 and 1900 [time since fire (TSF) $>100$ years], associated with the period of European settlement (Veblen et al. 2003) and two areas (Lago Gutierrez and Cerro Catedral) that burned in 1999 and 1996, respectively (TSF <20 years) (Bran et al. 1996; Salguero 2000). Forest remnants were easy to locate within the area burned less than 20 years ago, because they were immersed in a matrix of resprouting shrubs with smaller height and smaller trunk diameters (Online resource 3, Photo S1). In contrast, forest remnants are difficult to locate within the area burned 100 years ago, because the forest has already recovered and thus matrix trees have slightly lower height and smaller trunk diameter than trees within remnants (Online resource 3, Photo 2). Therefore, we used different methods to locate remnants depending on TSF, as explained below.

\section{Forest remnant vs. matrix at landscape scale}

For the area that burned between 1880 and 1900 (TSF > 100 years) we randomly selected 50 points within a map of the current distribution of A. chilensis forest which represents the post-fire expansion of the species in the study area. We visited only the points that were accessible by being less than $1 \mathrm{~km}$ from a road or track and we looked for forest remnants within a radius of about $1 \mathrm{~km}$ from each of these accessible points. Every time we found a forest remnant, we performed the field measurements (details below). Forest remnants were considered patches of live and visible old A. chilensis trees with fire scars and large diameters $(>30 \mathrm{~cm})$ that clearly differentiated from the surroundings which were composed of trees without fire scars and slightly smaller trunks. Patches of trees identified as remnants ranged in tree density from 119 to 3382 individual/ha (Online resource 2, Table S1).

In the areas that burned in 1996 and 1999 (TSF $<20$ years), we relied on high-resolution Quickbird images (available on Google Earth). The forest remnants were easily differentiated from the matrix in the images because of the hue and shape of the A. chilensis trees, which look darker than the shrubland matrix and have a conical shape (personal observation). Furthermore, all remnants were located over large rocky outcrops, which made them easier to find. All forest remnants identified through the images were visited in the field, and those patches which had live $A$. chilensis trees with fire scars and large diameters $(>15 \mathrm{~cm})$ were considered forest remnants. In total, we located 31 forest remnants throughout the national park: 24 within the area burned more than 100 years ago and seven in the area burned less than 20 years ago (Online resource 2, Table S1).

For all forest remnants we defined a paired matrix location at between 50 and $100 \mathrm{~m}$ in a random direction from the edge of the remnant. For each forest remnant and matrix location we obtained the normalized difference vegetation index (NDVI) of an autumn (2007) and summer (2006) ASTER image with $15 \mathrm{~m}$ ground resolution. As NDVI is a measure of greenness we considered that it was an effective method to explore if remnants and matrices could be differentiated by this index at a broad scale, and therefore, to infer if forest remnants were actually less vegetated (and thus less productive, with lower fire severity 
and higher tree survival probability) than the matrix. Altitude, aspect and slope were assessed using a digital elevation model (GDEM) (Tachikawa et al. 2011) with a horizontal resolution of $28.5 \times 28.5 \mathrm{~m}$ (Monmonier 1982). Aspect was transformed into easting and northing by taking the sine and cosine, respectively. All the layers were generated and processed using IDRISI Selva. Although we found 24 remnants in the older burns (TSF $>100$ ), we could not find paired nearby matrix points for three of them; therefore, to perform the analyses at the landscape scale we used 21 sample points. As the data came from paired matrix and forest remnant locations, we used paired $t$-tests to look for differences between them (Crawley 2007). We tested elevation, slope, autumn NDVI, summer NDVI, northing and easting. All variables were normally distributed. Furthermore, we performed a principal components analysis (PCA) to evaluate if matrices and forest remnants from the two burning periods differed in their association to the above listed variables. The number of sampling points in this PCA was 56 (TSF $>100, n=21$ matrix samples and $n=21$ remnants; TSF $<20$ years, $n=7$ matrix and $n=7$ remnants).

\section{Forest remnant vs. matrix at local scale}

To test the hypothesis in the field that forest remnants are less productive than the matrix, with a high rock to vegetation ratio and elevated topographical positions in landscape, we surveyed seven forest remnants in the area burned in 1996 and 1999 (TSF < 20 years; Cerro Catedral and Lago Gutierrez). The area of these remnants was between 1200 and $5800 \mathrm{~m}^{2}$. At a distance of $50 \mathrm{~m}$ from each forest remnant we randomly selected a survey point in the matrix. Both in the forest remnants and the matrix we located a $2 \times 10 \mathrm{~m}$ plot, where we measured elevation with a global positioning system (that included a barometric altimeter) and visually estimated herb, shrub, tree, bare soil and rocky cover. We also recorded vegetation height with a measuring tape. We performed paired $t$-tests to compare these variables between remnant $(n=7)$ and matrix plots $(n=7)$. Total vegetation height and herb cover were $\log$ transformed, whereas tree cover was square-root transformed to achieve normality. Furthermore, we conducted a PCA to evaluate if matrix $(n=7)$ and forest remnants $(n=7)$ differed in their association to the recorded biophysical attributes.

\section{Tree growth within forest remnants and matrices}

To determine if trees growing in forest remnants have different growth pattern compared to trees growing in the matrix (due to the hypothetical differences in site productivity) we cored trees growing in the 24 forest remnants and the 21 matrices in the area burned more than 100 years ago. We could not acquire cores from the matrix burned in 1996 and 1999 because this area did not present any live A. chilensis tree (except for seedlings or juvenile trees which were too small for coring). Thus, specifically within the forest remnants and matrices of the area burned 100 years ago, we randomly chose trees using the point-centered quarter method (Cottam and Curtis 1956). We selected the A. chilensis tree (diameter at breast height $>5 \mathrm{~cm}$ ) nearest to the center of each quadrant and recorded its diameter at coring height, the presence of fire scars, and measured the distance of the tree to the center of the plot to calculate tree density per site, sensu Cottam and Curtis (1956). We cored three $A$. chilensis trees at $40 \mathrm{~cm}$ above ground per matrix and remnant. We processed and measured all cores to determine tree age and ring widths (see Online resource 1 for coreprocessing details). We calculated basal area increment (BAI) per year per tree with the ring width and the diameter at coring height.

To assess if there were differences between tree growth of forest remnants and matrices, we conducted a linear mixed-effects model [lme function, nlme package (Pinheiro et al. 2011)] in $\mathrm{R}$ software version 3.0.2. The response variable (BAI) was log transformed to accomplish normality. The fixed effects were plot type (matrix or forest remnant), tree age, age squared (to obtain a quadratic function), tree density and temperature and precipitation from the growth year and the previous year of growth. Annual temperature was obtained by averaging monthly temperature of the growth period and annual precipitation by summarizing monthly precipitation of the same period (November-March). The interaction between tree density and plot was not significant, thus we excluded it from the model. The random effects were site $(n=24)$, plot $(n=45)$ and tree $(n=89)$. We modeled temporal autocorrelation with a corARMA structure (Zuur et al. 2009), as the data were compounded by yearly tree ring measurements. We calculated the conditional $R^{2}$ (sensu Nakagawa and Schielzeth 2013) to determine goodness-of-fit of the model. Furthermore, to assess if trees growing within forest remnants and matrices differed in the correlation between radial growth and climate, we conducted a correlation function analysis using the bootRes package of the $\mathrm{R}$ software (Zang and Biondi 2013). Tree-ring series were detrended using a cubic smoothing spline to remove low-frequency variance (Cook and Kairiukstis 1990). Then, we developed a residual chronology for forest remnants and another for matrices using the dplR package (Bunn 2008) of the R software and calculated the mean sensitivity of series (Douglass 1920). A tree ring chronology consists of a series of measured tree ring widths that are converted to a dimensionless index through standardization. This index is the ring width index (RWI), which represents departures of growth compared to 
average growth. The mean sensitivity is a standard dendrochronological measure developed to estimate the sensitivity of tree series to climate trough the quantification of the relative change in RWI from one year to the next (Douglass 1920). Mean monthly precipitation and temperature data (1931-2011) were obtained from the Bariloche meteorological station, which provided climatic data representative of the whole study area. The analysis included monthly temperature and precipitation from October of the previous year of growth to May of the current growth year.

\section{Tree survival and microsite attributes}

To determine the attributes that could allow isolated trees or clusters of trees to survive fire, we worked in the area burned in 1999 and 1996 (TSF < 20 years) (Lago Gutierrez and Cerro Catedral). Working in a recently burned area allowed us to find standing dead trees, which are absent in the area burned more than 100 years ago. We randomly selected isolated and clusters of standing dead and live trees around and within the forest remnants.

We selected 33 dead and 33 live trees, standing more than $2 \mathrm{~m}$ away from any other tree and measured diameter at $40 \mathrm{~cm}$ above ground. Furthermore, we recorded altitude, aspect and slope of the place where the tree was standing. We only cored live individuals to determine tree age and to corroborate if these were actually fire survivors (i.e., 33 trees were cored $40 \mathrm{~cm}$ above ground). We located a circular plot of $2 \mathrm{~m}$ in diameter surrounding every tree and divided each plot into four quadrants. Within each quadrant we visually estimated the cover of bare soil, trees, shrubs, herbs, total vegetation and rocks. Furthermore, we recorded the height of trees, shrubs, herbs and total vegetation with a measuring tape and soil depth with a $1.5 \mathrm{~m}$ metal stick marked every $5 \mathrm{~cm}$. In order to test if tree diameter affected survival probability, we estimated the diameter of live trees at the time of the fire. For this, we determined how much surviving trees grew in diameter after fire, by measuring with a caliper the ring widths produced after fire. Then, we subtracted the total width produced after fire from its diameter at coring height. This allowed us to compare the diameter of live trees at the moment of fire occurrence with that of the trees that died during the fire.

In addition, we located 11 clusters of standing dead and 11 clusters of surviving trees. These clusters were composed of three to five trees standing relatively close together. We randomly located between three and five $1 \mathrm{~m}^{2}$ circular plots within each cluster, depending on the size of the cluster. In each plot we recorded the same attributes as those registered in the isolated tree plots and topographic position (foothill, lower hill, mid-hill, upper hill or hilltops).

To assess the probability of fire survival of the isolated trees $(n=66)$ and clusters of trees $(n=22)$ we estimated generalized linear models (package glm; R Software) with binomial distribution (logit link). The isolated trees model contained diameter at coring height, soil depth, rocky cover, slope, elevation, total vegetation cover, total vegetation height, northing and easting (the last two derived from aspect) as independent variables. The clusters of trees model contained northing, easting, elevation, slope, topographical position, soil depth, total vegetation cover and total vegetation height. Shrub and herb height, and shrub, herb and rocky cover were eliminated from the last model because they were highly correlated with the other variables. Only variables with a variance inflation factor of three or less were included.

\section{Results}

\section{Forest remnant vs. matrix at landscape scale}

The first two principal components of the PCA at the landscape scale explained 38.2 and $26.8 \%$, respectively, of the total variation in the environmental attributes; however, neither of the two axes served to discriminate forest remnants from matrices (Online resource 2, Fig. S1, Table S2). Regarding the paired $t$-tests, only autumn NDVI was significantly higher in the matrix than in the forest remnant (Online resource 2, Table S3).

\section{Forest remnant vs. matrix at local scale}

Compared to the poor discrimination of the PCA conducted at the landscape scale, important biophysical differences between forest remnants and matrices emerge when analyzed at the local scale (Fig. 1). The first principal component (PC1) accounted for $50 \%$ of the total variation with good discrimination between forest remnants and matrices, whereas the second axis (PC2) explained $18 \%$ of the variation with poor discrimination (Online resource 2, Table S4). Forest remnants were more associated with elevation, rocky cover and bare soil, whereas matrices were related to vegetation height and cover. What is more, according to the paired $t$-test, forest remnants had significantly greater rocky cover and were located at marginally higher elevation than matrices $(P=0.03$ and $P=0.085$, respectively; Online resource 2, Table S5). Matrix understories were significantly taller and displayed higher total cover than forest remnant understories $(P<0.001$ and $P=0.001$, respectively). Many of these effects were accounted for by matrices having significantly taller shrubs $(P<0.001)$ and marginally larger shrub and herb cover ( $P=0.083$ and $P=0.059$, respectively) than forest remnants. 


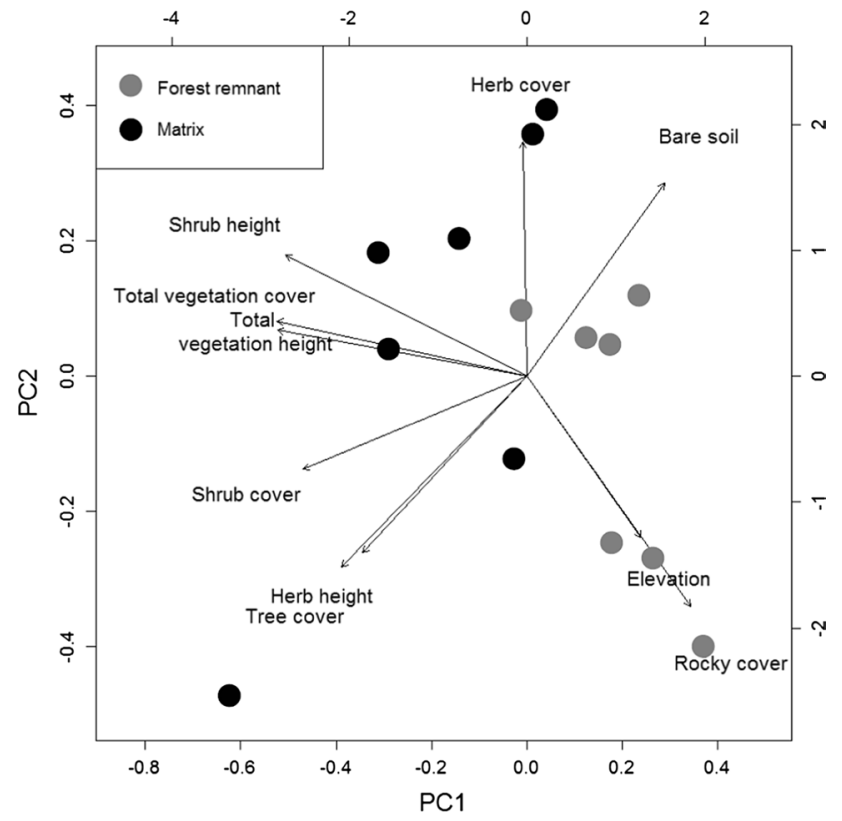

Fig. 1 At the local scale, the principal component analysis (PCA) displayed a clear differentiation between forest remnants (grey) and matrices (black) in rocky cover, elevation, bare soil, vegetation cover and height. The variables are represented by arrows and the sites by dots $(n=14)$. Relative loadings of the variables on the first $(P C 1)$ and second principal components $(P C 2)$ are shown by arrows direction and length

\section{Tree growth within forest remnants and matrices}

Larger/fire-scarred A. chilensis trees growing within forest remnants were on average almost twice as old as trees growing within matrices (125 and 72 years old, respectively; Online resource 2, Table S1). Furthermore, A. chilensis trees growing in forest remnants and matrices showed important differences in their radial growth and their response to climatic variability (Fig. 2). The forest remnant tree ring chronology showed a c. $20 \%$ higher mean sensitivity in ring width index (RWI) than the matrix tree chronology (Online resource 2, Table S6). Accordingly, in forest remnants, trees showed a stronger reduction in radial growth (i.e., ring width index) in response to documented regional drought events compared to a more complacent growth pattern of matrix trees (Fig. 2). Two of the strongest most persistent droughts of the last 100 years (1911 and 1998; <-2 SD of April-December mean precipitation) impacted similarly on the growth of trees in both forest remnants and matrices. Conversely, more moderate winterspring drought events (1922, 1943, 1957, 1962 and 2008) resulted in a stronger reduction (0.09-0.19) of the RWI in remnant trees than that in matrix trees (Fig. 2). Strikingly, the last two droughts (1998 and 2008) associated with extremely warm summer conditions $(+2.3$ and +1.9 SD of December-February mean temperature, respectively)
Fig. 2 a Austrocedrus chilensis trees growing within forest remnants (grey) displayed extremely lower growth rates (ring width index) during drought years (vertical arrows) compared to A. chilensis trees growing within matrices (black). Small black arrows indicate drought years and large black arrows show two of the strongest droughts of the last 100 years. b Number of series (sample depth) per matrix (black) and forest remnant (grey) which compounded the residual chronologies
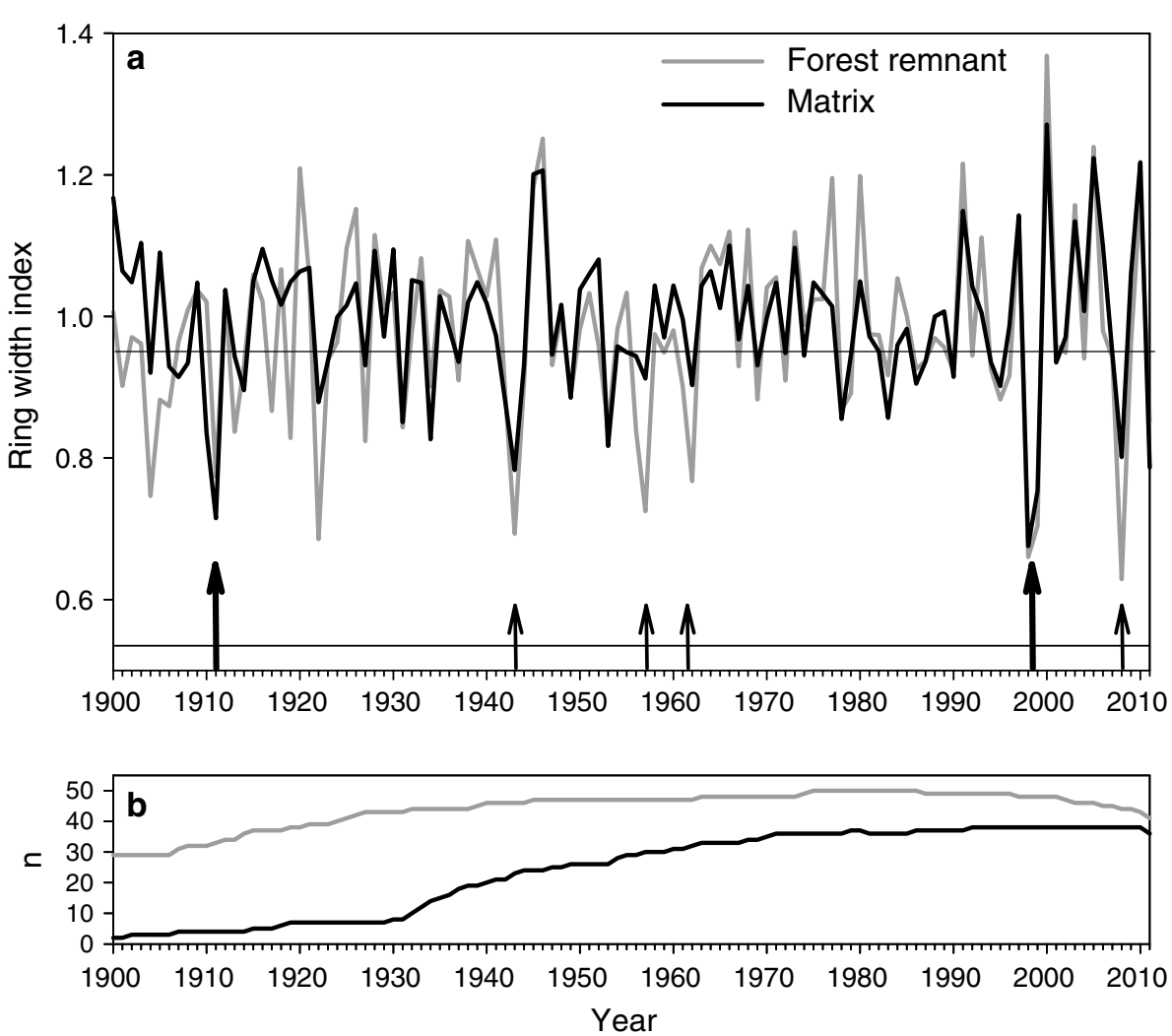


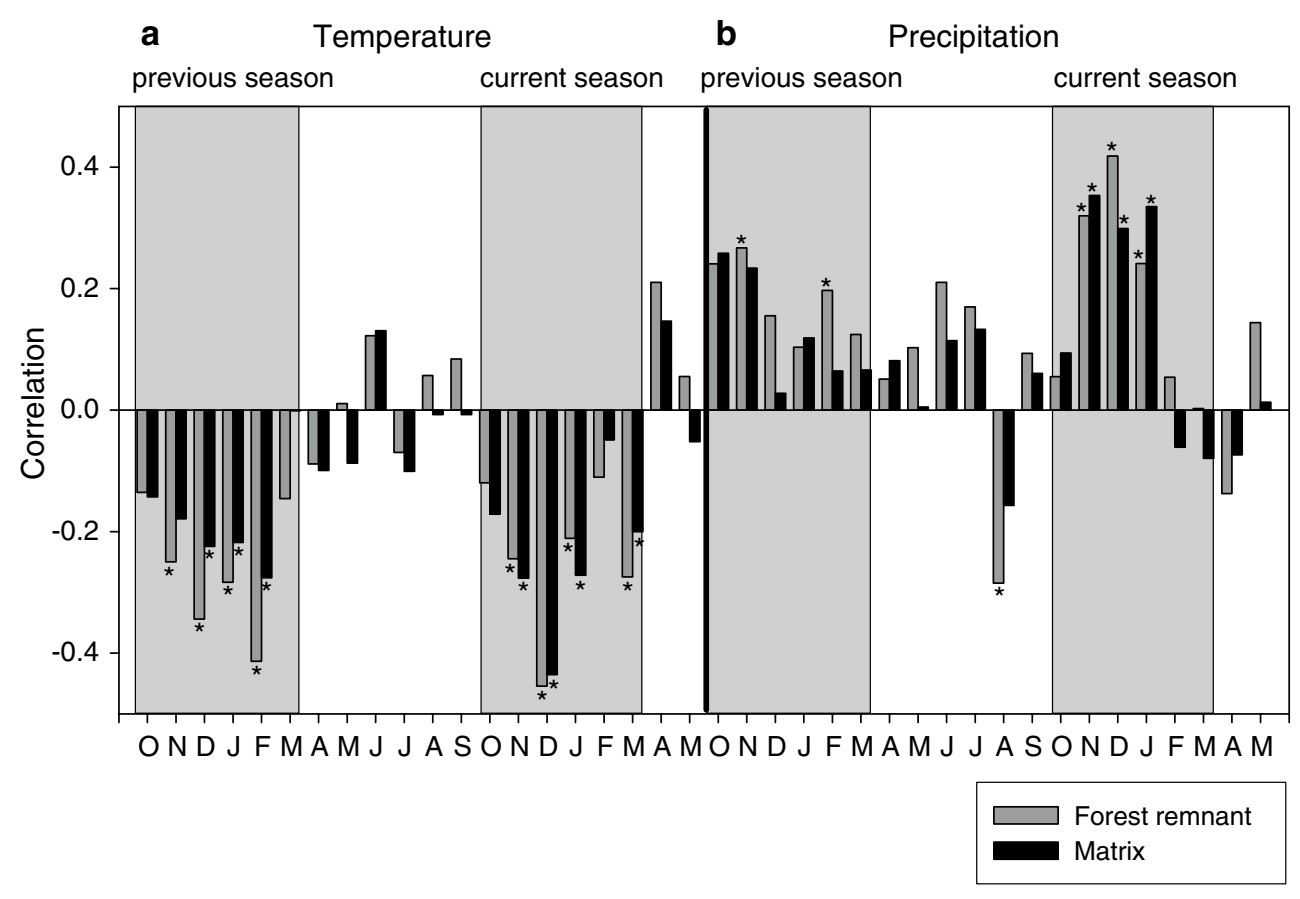

Fig. 3 Correlation functions showing more negative correlations between radial growth and a temperature and more positive correlations with $\mathbf{b}$ precipitation of the previous season for A. chilensis trees within forest remnants (grey) $(n=50)$ than within matrices (black) $(n=39)$. Months are shown on the $x$-axes, where the first October-

generated the strongest impacts on radial growth, particularly in trees located in remnants.

Correlation function analysis showed a common general response of trees in remnants and in matrices to monthly climatic variables. However, it also highlighted important differences between them. Overall, the growth of both patches of trees showed a positive correlation with spring-early summer precipitation (October-January) and negative with spring-summer temperature (November-February) during the current and the preceding season (Fig. 3). However, correlation coefficients between radial growth and temperature of the previous season (November-February) were ca. 30-50 \% more negative for trees in forest remnants compared to trees within matrices. Likewise, positive correlations between growth and precipitation were higher for forest remnants during November and February of the previous season (Fig. 3). Correlations with current season climate did not show important differences between forest remnants and matrix trees (except for the high correlation between December temperature and growth of trees within remnants). Surprisingly, August precipitation (snow) was highly negatively correlated with tree growth within forest remnants.

When the annual BAI was compared between forest remnants and matrices, trees growing within forest remnants showed consistently larger BAI than those in matrices during much of the mid twentieth century (Fig. 4). This
May $(O, N, D, J, F, M, A, M)$ period corresponds to the year prior to growth (previous season) and the second October-May period corresponds to the growth year (current season). Asterisks indicate significant correlations

was supported by the linear mixed-effects model, which explained $84 \%$ of the variation in BAI and accounted for a significantly higher BAI in forest remnants $(P=0.0009)$ (Online resource 2, Table S7). However, starting after the droughts of 1957-1962, a declining trend in BAI in forest remnants has led to similar annual BAI for both patches of trees during the last decade. The differences in growth were not explained by differences in the average age of trees because trees within forest remnants had consistently higher annual BAI than trees of the same ages growing in matrices (Online resource 2, Fig. S2). Trees in forest remnants tended to decrease annual BAI with age whereas trees in matrices showed an increase followed by a slow decline so that ca. 100-year-old trees growing in forest remnants had similar mean BAI to ca. 30-year-old trees in matrices $(P=0.0001)$. Also, the effect of stand density on tree BAI was not significant. Similar to what we found with correlation function analyses, both precipitation of the prior and the current year of growth had a positive effect on tree BAI, and temperature of the prior and current year of growth had a negative effect $(P=0.0001)$.

\section{Tree survival and microsite attributes}

Isolated and clusters of trees differed in fire survival probability depending on the biophysical attributes around 
Fig. 4 A. chilensis trees growing within remnants (grey) displayed higher basal area increment (BAI) than A. chilensis trees growing within matrices (black) which extended for almost all the period of study. Points represent mean BAI and vertical lines are $\pm \mathrm{SE}, n=89$

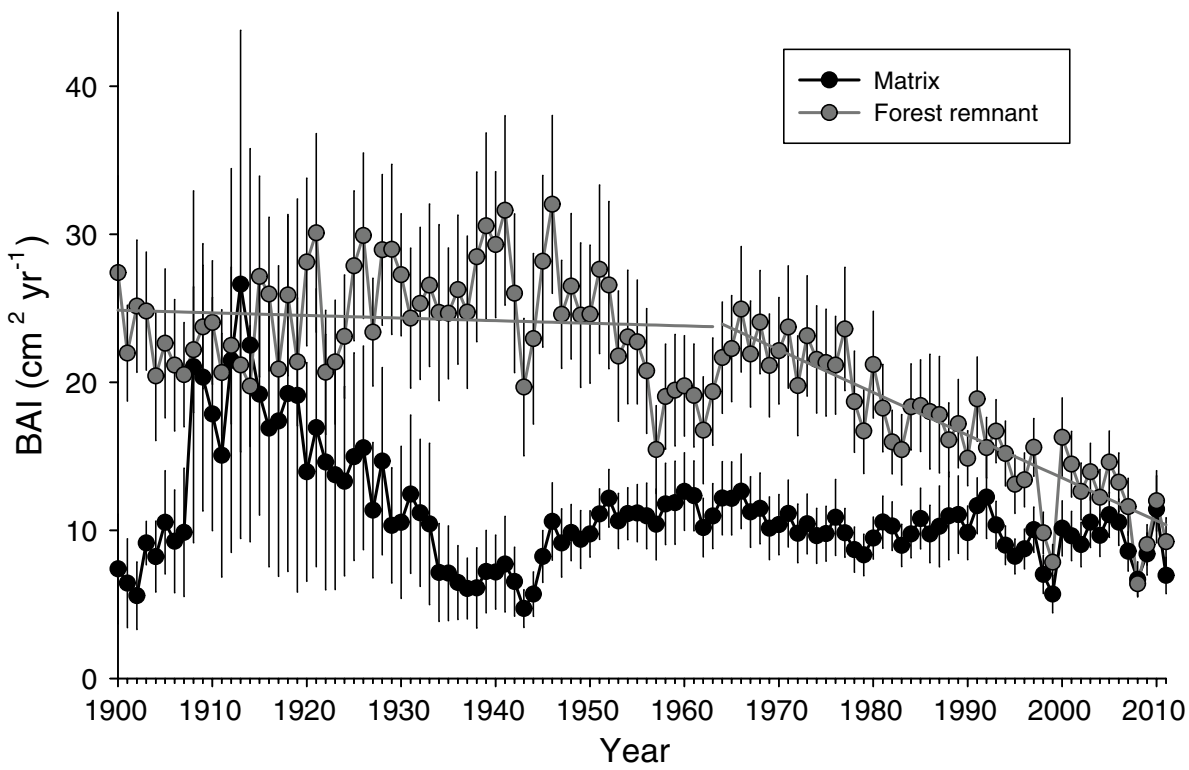

them. The generalized linear models showed that clusters of trees located at high topographic positions in the landscape (upper hills and hilltops) had a marginally greater fire survival probability than clusters of trees located in foothills, lower and mid-hills $(P=0.079)$ (Online resource 2, Table S8). This relationship was asymmetric: none of the clusters of trees survived fire in lower topographic positions but some clusters at upper positions were killed by the fire. Moreover, isolated trees showed higher probability of survival in easterly aspects, while westerly located trees tended to show higher mortality $(P=0.018)$ (Online resource 2, Table S8). Furthermore, in contrast to clusters, isolated trees surrounded by vegetation presented lower survival probability $(P=0.032)$, and when discriminating between different vegetation strata, shrub cover displayed a marginal effect on tree death $(P=0.069$, data not shown). Surprisingly, rocky cover and diameter at breast height had no effect on tree survival $(P=0.64$ and $P=0.21$, respectively).

\section{Discussion}

Our results indicate that $A$. chilensis forest remnants were actually the result of deterministic fire refuges rather than a stochastic residual of the last fire. Fire, interacting with certain components of the biophysical landscape heterogeneity, generates distinct and spatially fixed entities (fire refuges) where fire-sensitive obligate seeder trees such as A. chilensis are able to increase both fire survivorship and growth at the cost of a higher vulnerability to drought. These pervasive refuges throughout the landscape have allowed A. chilensis to persist during periods of frequent and extensive fires. Also by serving as seed sources they allowed the recolonization of large areas dominated by resprouting shrubs during periods of low fire activity (Fig. 5). Remnants displayed attributes associated with lower flammability than matrices, which may have reduced fire severity. This strongly suggests that fire may behave differently throughout these contrasting places, allowing trees to reach higher survival probability within refuges.

At the landscape scale, low autumn NDVI was the only attribute discriminating remnants from matrices. This occurred despite the fact that matrices have intrinsically low autumn NDVI as they tend to be dominated by the deciduous shrub Nothofagus antarctica. Thus, even having a higher dominance of evergreen plants, remnants have lower autumn NDVI than the deciduous-dominated matrices, suggesting low vegetation cover and high cover of rocky surfaces in remnants. However, differences in NDVI tended to blur in summer. Perhaps increases in overall NDVI due to maximal seasonal cover, growth and vigor could be masking the importance of low cover substrate, an attribute that may only emerge when NDVI decreases. It is also possible that the coarse spatial resolution of the analysis generated mixed NDVI signatures (Dean and Smith 2003) or poorly resolved topographic features, thus reducing the explanatory power of the variables that could discriminate remnants from matrices (e.g., NDVI, slope, elevation, aspect).

At the local scale, we found forest remnants to be associated with elevated topographic positions and rocky conditions with low shrub cover and low shrub height. This strongly suggests that topography and substrate may be imposing restrictions to fire spread (Camp et al. 1997; Clarke 2002a; Wood et al. 2011; Leonard et al. 2014). 


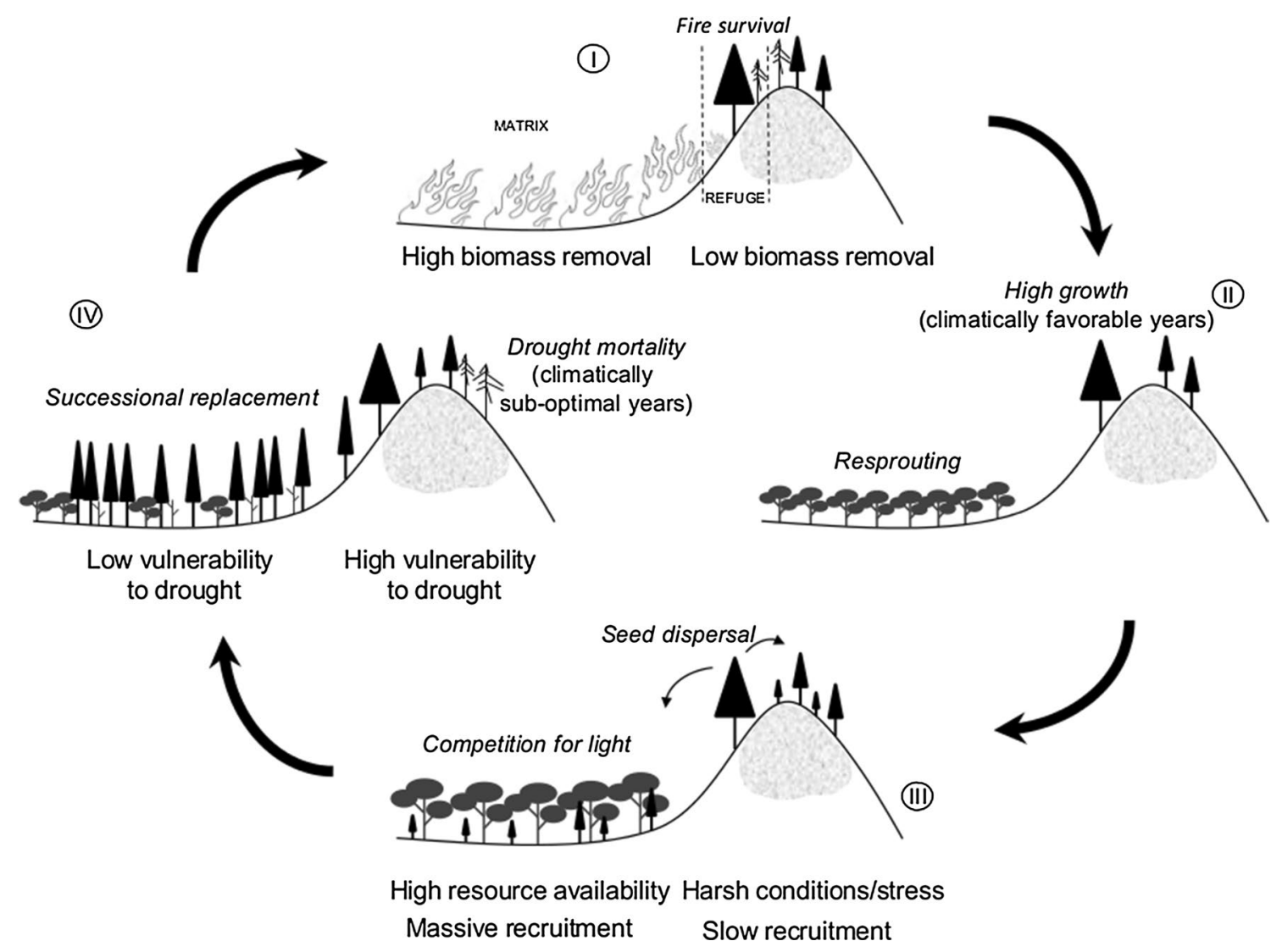

Fig. 5 Diagram summarizing the successional cycle between $A$. chilensis (conical tree) and resprouter shrub species after fire. The processes (in italic) are specific for each successional stage or climatic condition, while the attributes of refuges and matrices are intrinsic to the site, and thus present in all successional stages. Here, they appear in specific successional stages only for simplification. I Fire attains high severity within the matrix producing high biomass removal, but enters the refuge and the rocky outcrop with lower severity allowing some trees to survive. II Some years after fire, shrub species resprout and dominate the matrix. A. chilensis trees display high growth rates during climatically favorable years, given the lower tree density and

Convex positions may reduce fire severity and rate of spread. Even though forest remnants were strongly associated with elevated topographical positions, a substantial number of the A. chilensis remnants were located in the immediate boundary between rocky outcrops and the matrix, typically downhill from the outcrop (personal observation). The location of remnants adjacent to rocky outcrops may provide physical barriers to fire, therefore allowing for moderate levels of biomass removal (Hunter 2003). Furthermore, this location supports reduced fuel loads by imposing restrictions to resprouting, plant establishment and growth, thus generating reduced fire frequency and severity (Hunter 2003; Clarke 2002a).

Trees growing within forest remnants were older than those within the surrounding matrix and, more importantly, the increasing water and nutrient supply that leach from the rocky outcrop. III A. chilensis seeds are dispersed by wind and seedlings regenerate beneath the shrub canopy within the matrix. High resource availability allows for massive recruitment and dense vegetation, increasing competition for light. Conversely, recruitment within the rocky outcrop is poor because of the harsh and stressful conditions. $I V$ A. chilensis exceeds the shrub canopy, allowing for a successional replacement within the matrix. A. chilensis trees growing within the refuge are more vulnerable to drought, which increases mortality probability during climatically sub-optimal years

trees in forest remnants preceded the European settlement period (1880-1920), thus suggesting that they effectively survived the time of most extensive and frequent forest burning in northern Patagonia (Veblen et al. 2003). Abundant younger trees ( $<90$ years old) located within the matrix further suggest that trees growing within forest remnants subsequently functioned as seed sources effectively dispersing and regenerating $A$. chilensis forests well into the shrub-dominated landscape matrix (Fig. 5). This mechanism where microrefuge networks (sensu Mackey et al. 2012) produced an overwhelming effect on forest expansion may explain the paradoxically fast A. chilensis twentieth century expansion rate (Gowda et al. 2012). Trees growing within forest remnants often had more than one fire scar, reflecting survival through several fire events 
(Online resource 2, Table S1). This shows that trees survived repeated fires, most likely by virtue of the low fire severity in remnants, which can therefore be considered as proper refuges. This fine-scale pattern of the same tree surviving subsequent fires could be the result of several non-mutually exclusive mechanisms that may involve fuellimited micro-environmental conditions that decrease fire severity and higher resource availability that allows for larger and more resistant tree size.

Indeed, trees within forest remnants displayed two- to threefold larger individual annual BAI than matrix trees, even after controlling for the older age (and thus larger size) of remnant trees (Online resource 2, Fig. S2). Nearness to rocky outcrops (generally around the base) may allow trees to receive extra water resulting from high runoff as well as elevated nutrient sources (e.g., $\mathrm{N}$ from biofilms) largely unavailable to trees growing in the middle of the rocky outcrop or in the matrix (Szarzynski 2000; Büdel et al. 2000). In addition, adequate microsites for tree seedling establishment are scarce within rocky outcrops resulting in low tree density and improved light conditions for each individual tree (Fig. 5). Faster growing trees may attain fire-resistant sizes more rapidly, thus increasing fire survival probabilities (Ordóñez et al. 2005; Lawes et al. 2011). Although in our study forest remnants and matrices did not differ in tree density, during the years following fire tree density may have been higher in the matrix, due to rapid post-fire revegetation, compared to the slower regeneration within outcrops given their limited conditions. Thus the few individuals that were able to establish in the outcrop and the ones that survived the fire may have grown in a place with less competition thus reaching higher annual BAI. Conversely, competition with shrubs in the matrix may be part of the explanation for lower BAI in matrix trees (Fig. 5).

Despite having higher long-term mean growth rates than matrix trees, trees in forest remnants were more susceptible to climatic variability. Overall, remnant tree growth was more sensitive to inter-annual variability in temperature and precipitation, a pattern already found in similar systems (Houle and Delwaide 1991). Forest remnant trees showed more marked growth reductions in response to historic droughts, particularly when drought events extended for more than 1 year. As evident from correlation functions, remnant tree growth showed a more persistent climatic signal that extended into the previous growing season. This suggests a longer time scale of integration of below-ground resources due to deeper root systems than in matrix trees, which possibly tap deep underground water of rocky outcrops. Thus, once these deep-water resources are depleted during long-term droughts, higher evaporative demands of rocky outcrop microsites may determine stronger water deficits in remnant than in matrix trees (Villalba and Veblen 1997; Szarzynski 2000). This may be the mechanism that explains well-documented massive drought-related mortality events of A. chilensis that occurred on ridges or outcrops during multi-year droughts (Villalba and Veblen 1998). The negative response of remnant tree growth to August precipitation can be explained by the accumulation of snow and ice that may produce cambium damage (Homma 1997), negatively affecting radial tree growth, particularly for trees growing within outcrops which are more exposed to adverse climate conditions.

Regarding survival probability at microsites, clusters of trees had higher probability of survivorship at hilltops, most likely because the probability of fire occurrence decreases with increasing elevation, due to a reduction in vegetation cover and thus in fuel loads (Wood et al. 2011). On the other hand, A. chilensis trees growing alone had a higher probability of survivorship when surrounded by sparse vegetation and positioned on eastern aspects, probably because they may be naturally protected by the hill from the predominantly regional west to east winds and thus from fire. However, contrary to our expectations, neither rocky cover nor being positioned on steep slopes increased isolated tree survivorship, although rocky cover was strongly associated with A. chilensis forest remnants. This suggests that there might be another attribute, other than rocky cover, which may be allowing trees to survive fire (e.g., being positioned on easterly aspects). Finally, opposed to what has been found for other tree species (Ordóñez et al. 2005; Lawes et al. 2011), tree diameter did not affect $A$. chilensis survivorship, which may be due to its thin bark. Therefore, we consider that tree survivorship is more associated with the "within-refuge heterogeneity" (i.e., shrubs and herbaceous vegetation cover, and topography) and weather conditions during the fire than with inherent traits of the tree (Perera et al. 2009).

\section{Conclusion}

We found that $A$. chilensis forest remnants in northwestern Patagonia are actually persistent entities, i.e., fire refuges, because they were associated with particular biophysical attributes which deterministically explained how trees growing within these locations survived multiple fire events. We also found that these refuges are functionally important because, besides the capacity of exerting protection to fire-sensitive trees, individual trees growing within them displayed greater growth rates than trees growing within matrices, probably due to reduced competition for light as a consequence of lower stand density and/or due to higher belowground resource availability. However, while trees in refuges had strong positive growth responses to climatically favorable wet years and high mean long-term growth rates, they also had drastically reduced growth rates during droughts. Therefore, refuges in this region could 
become extremely harsh and risky environments during droughts as they may increase the likelihood of droughtinduced tree mortality (Villalba and Veblen 1998). Given the concomitant trends of increasing drought and fire severity due to climate change (IPCC 2007; Flannigan et al. 2009), forest fire refuges will be essential for obligate seeding fire-sensitive species' persistence, since they act as the "ecological memory" of the landscape (Turner et al. 1998). However, our results underscore the existence of a tradeoff that may be involved in refuge functioning: specific biophysical attributes may improve conditions for fire survival and growth during climatically favorable periods, but also increase the vulnerability to droughts (Mackey et al. 2012). This trade-off may present significant challenges for the conservation of fire-sensitive forest taxa since refuges may turn into a less resilient mechanism for persistence under future climatic scenarios.

Acknowledgments We thank Juan Manuel Morales for insightful comments on the manuscript and Maria Laura Suarez for her help in the tree chronology and correlation function analysis. We especially thank Jeremy Lichstein (handling editor) and two anonymous reviewers for their comments which greatly improved the quality of the manuscript. This study was funded by grant BIRF 7520 (Sustainable Forests Plantations Component) PIA 10058 and PIA 12055 (Ministerio de Agricultura, Ganadería y Pesca). J.B.L. acknowledges a CONICET fellowship.

Author contribution statement J.B.L. performed the research, conducted fieldwork, analyzed the data and wrote the manuscript. J.B.L., J.H.G. and T.K. conceived and designed the study. L.A.G. contributed to the data analysis.

\section{Compliance with ethical standards}

Conflict of interest The authors declare that they have no conflict of interest and that the experiments comply with the current laws of Argentina, where the experiments were performed.

\section{References}

Bengtsson J, Angelstam P, Elmqvist T, Emanuelsson U, Folke C et al (2003) Reserves, resilience and dynamic landscapes. Ambio 32(6):389-396. doi:10.1579/0044-7447-32.6.389

Bessie WC, Johnson EA (1995) The relative importance of fuels and weather on fire behavior in subalpine forests. Ecology 76:747762. doi:10.2307/1939341

Bran D, Ayesa J, López C, Sbriller D (1996) Evaluación del área afectada por el incendio de enero de 1996 en Co. Catedral. Laboratorio de Teledetección Aplicada, INTA EEA Bariloche

Büdel B, Becker U, Follmann G, Sterflinger K (2000) Algae, fungi, and lichens on inselbergs. In: Porembski S, Barthlott W (eds) Inselbergs: biotic diversity of isolated rock outcrops in tropical and temperate regions. Springer, Heidelberg, pp 69-90

Bunn AG (2008) A dendrochronology program library in R (dplR). Dendrochronologia 26(2):115-124. doi:10.1016/j. dendro.2008.01.002

Camp A, Oliver C, Hessburg P, Everett R (1997) Predicting latesuccessional fire refugia pre-dating European settlement in the wenatchee mountains. For Ecol Manage 95(1):63-77. doi:10.1016/S0378-1127(97)00006-6

Clarke PJ (2002a) Habitat islands in fire-prone vegetation: do landscape features influence community composition? J Biogeogr 29(5/6):677-684. doi:10.1046/j.1365-2699.2002.00716.x

Clarke PJ (2002b) Habitat insularity and fire response traits: evidence from a sclerophyll archipelago. Oecologia 132(4):582-591. doi:10.1007/s00442-002-0962-0

Cook ER, Kairiukstis LA (1990) Methods of dendrochronology: applications in the environmental sciences. Springer, Heidelberg

Cottam G, Curtis JT (1956) The use of distance measures in phytosociological sampling. Ecology 37:451-460. doi:10.2307/1930167

Crawley MJ (2007) The R book. Wiley, New York

De Long SC, Kessler WB (2000) Ecological characteristics of mature forest remnants left by wildfire. For Ecol Manage 131(1):93106. doi:10.1016/S0378-1127(99)00203-0

Dean AM, Smith GM (2003) An evaluation of per-parcel land cover mapping using maximum likelihood class probabilities. Int J Remote Sens 24(14):2905-2920. doi:10.1080/01431160210155910

Douglass AE (1920) Evidence of climatic effects in the annual rings of trees. Ecology 1:24-32. doi:10.2307/1929253

Elmqvist T, Wall M, Berggren AL, Blix L, Fritioff A, Rinman U (2001) Tropical forest reorganization after cyclone and fire disturbance in Samoa: remnant trees as biological legacies. Conserv Ecol 5(2): 10

Flannigan MD, Krawchuk MA, de Groot WJ, Wotton BM, Gowman LM (2009) Implications of changing climate for global wildland fire. Int J Wildland Fire 18:483-507. doi:10.1071/WF08187

Gowda JH, Kitzberger T, Premoli AC (2012) Landscape responses to a century of land use along the northern Patagonian foreststeppe transition. Plant Ecol 213(2):259-272. doi:10.1007/ s11258-011-9972-5

Homma K (1997) Effects of snow pressure on growth form and life history of tree species in Japanese beech forest. J Veg Sci 8:781788. doi: $10.2307 / 3237022$

Houle G, Delwaide A (1991) Population structure and growth-stress relationship of Pinus taeda in rock outcrop habitats. J Veg Sci 2:47-58. doi: $10.2307 / 3235897$

Hunter JT (2003) Persistence on inselbergs: the role of obligate seeders and resprouters. J Biogeogr 30(4):497-510. doi:10.1046/j.1365-2699.2003.00876.x

Intergovernmental Panel on Climate Change (2007) Climate change 2007: The IPCC fourth assessment report. Cambridge University Press, Cambridge

Keppel G, Wardell-Johnson GW (2012) Refugia: keys to climate change management. Glob Change Biol 18(8):2389-2391. doi:10.1111/j.1365-2486.2012.02729.x

Kitzberger T, Veblen TT (1999) Fire-induced changes in northern Patagonian landscapes. Landscape Ecol 14:1-15. doi:10.102 3/A:1008069712826

Kitzberger T, Aráoz E, Gowda JH, Mermoz M, Morales JM (2012) Decreases in fire spread probability with forest age promotes alternative community states, reduced resilience to climate variability and large fire regime shifts. Ecosystems 15(1):97-112. doi:10.1007/s10021-011-9494-y

Lawes MJ, Adie H, Russell-Smith J, Murphy B, Midgley JJ (2011) How do small savanna trees avoid stem mortality by fire? The roles of stem diameter, height and bark thickness. Ecosphere 2(4):art42. doi:10.1890/ES10-00204.1

Leonard SW, Bennett AF, Clarke MF (2014) Determinants of the occurrence of unburnt forest remnants: potential biotic refuges within a large, intense wildfire in south-eastern Australia. For Ecol Manage 314:85-93. doi:10.1016/j.foreco.2013.11.036

Mackey B, Berry S, Hugh S, Ferrier S, Harwood TD, Williams KJ (2012) Ecosystem greenspots: identifying potential drought, fire, 
and climate-change micro-refuges. Ecol Appl 22(6):1852-1864. doi:10.1890/11-1479.1

Mermoz M, Kitzberger T, Veblen TT (2005) Landscape influences on occurrence and spread of wildfires in patagonian forests and shrublands. Ecology 86(10):2705-2715. doi:10.1890/04-1850

Monmonier MS (1982) Computer-assisted cartography: principles and prospects. Prentice-Hall, Englewood Cliffs, NJ, pp 76-80

Nakagawa S, Schielzeth H (2013) A general and simple method for obtaining $R^{2}$ from generalized linear mixed-effects models. Methods Ecol Evol 4(2):133-142. doi:10.1111/j.2041-210x.2012.00261.x

Newton A et al. (2011) Landscape-scale dynamics and restoration of dryland forest ecosystems. In: Newton A, Tejedor N (eds) Principles and practice of forest landscape restoration: case studies from the drylands of Latin America. International Union for Conservation of Nature, pp 229-272

Ordóñez JL, Retana J, Espelta JM (2005) Effects of tree size, crown damage, and tree location on post-fire survival and cone production of Pinus nigra trees. For Ecol Manage 206(1):109-117. doi:10.1016/j.foreco.2004.10.067

Perera AH, Dalziel BD, Buse LJ, Routledge RG (2009) Spatial variability of stand-scale residuals in Ontario's boreal forest fires. Can J For Res 39(5):945-961. doi:10.1139/X09-024

Pinheiro J, Bates D, DebRoy S, Sarkar D (2011) R Development Core Team 2010, nlme: linear and nonlinear mixed effects models. $\mathrm{R}$ package version 3.1-97. R Foundation for Statistical Computing, Vienna

Robinson NM, Leonard SW, Ritchie EG, Bassett M, Chia EK, Buckingham S, Gibb H, Bennett AF, Clarke MF (2013) Refuges for fauna in fire-prone landscapes: their ecological function and importance. J Appl Ecol 50(6):1321-1329. doi:10.1111/1365-2664.12153

Robinson NM, Leonard SW, Bennett AF, Clarke MF (2014) Refuges for birds in fire-prone landscapes: the influence of fire severity and fire history on the distribution of forest birds. For Ecol Manage 318:110-121. doi:10.1016/j.foreco.2014.01.008

Román-Cuesta RM, Gracia M, Retana J (2009) Factors influencing the formation of unburned forest islands within the perimeter of a large forest fire. For Ecol Manage 258(2):71-80. doi:10.1016/j. foreco.2009.03.041

Salguero J (2000) Informe sobre las consecuencias ecológicas de los incendios forestales. APN, Delegación Regional Patagonia, Ecología del Fuego

Schwilk DW, Keeley JE (2006) The role of fire refugia in the distribution of Pinus sabiniana (Pinaceae) in the southern Sierra Nevada. Madrono 53(4):364-372. doi:10.3120/0024-9637(2006)

Souto C, Gardner M (2013) Austrocedrus chilensis. The IUCN red list of threatened species, version 2014.3

Szarzynski J (2000) Xeric islands: environmental conditions on inselbergs. In: Porembski S, Barthlott W. (eds) Inselbergs: biotic diversity of isolated rock outcrops in tropical and temperate regions. Springer, Heidelberg, p 37-48

Tachikawa T, Hato M, Kaku M, Iwasaki A (2011) The characteristics of ASTER GDEM version 2, IGARSS, pp 3657-3660 doi: 10.1109/IGARSS.2011.6050017

Turner MG, Baker WL, Peterson CJ, Peet RK (1998) Factors influencing succession: lessons from large, infrequent natural disturbances. Ecosystems 1:511-523. doi:10.1007/s100219900047

Uhl C, Kauffman JB (1990) Deforestation, fire, susceptibility, and potential tree responses to fire in the eastern Amazon. Ecology 71:437-449. doi:10.2307/1940299

Van Wilgen BW, Higgins KB, Bellstedt DU (1990) The role of vegetation structure and fuel chemistry in excluding fire from forest remnants in the fire-prone fynbos shrublands of South Africa. J Ecol 78:210-222

Veblen TT, Lorenz DC (1988) Recent vegetation changes along the forest/steppe ecotone in northern Patagonia. Ann Assoc Am Geogr 78:93-111. doi:10.1111/j.1467-8306.1988.tb00193.x

Veblen TT, Kitzberger T, Raffaele E, Lorenz D (2003) Fire history and vegetation changes in northern Patagonia, Argentina. In: Veblen TT, Baker W, Montenegro G, Swetnam TW (eds) fire and climatic change in temperate ecosystems of the western Americas. Ecological studies, vol 160. Springer, Heidelberg, pp 265-295

Veblen TT, Kitzberger T, Raffaele E, Mermoz M, González ME, Sibold JS, Holz A (2008) The historical range of variability of fires in the Andean-Patagonian Nothofagus forest region. Int J Wildland Fire 17(6):724-741

Villalba R, Veblen TT (1997) Spatial and temporal variation in Austrocedrus growth along the forest steppe ecotone in northern Patagonia. Can J For Res 27(4):580-597. doi:10.1139/ cjfr-27-4-580

Villalba R, Veblen TT (1998) Influences of large-scale climatic variability on episodic tree mortality in northern Patagonia. Ecology 79:2624-2640. doi:10.1890/0012-9658(1998)

Willis B (1914) El Norte de la Patagonia. Dirección de Parques Nacionales, Buenos Aires

Wood SW, Murphy BP, Bowman DM (2011) Firescape ecology: how topography determines the contrasting distribution of fire and rain forest in the south-west of the Tasmanian Wilderness World Heritage area. J Biogeogr 38(9):1807-1820. doi:10.1111/j.1365-2699.2011.02524.x

Zang C, Biondi F (2013) Dendroclimatic calibration in R: the bootRes package for response and correlation function analysis. Dendrochronologia 31(1):68-74. doi:10.1016/j.dendro.2012.08.001

Zuur A, Ieno EN, Walker N, Saveliev AA, Smith GM (2009) Mixed effects models and extensions in ecology with R. Springer, Heidelberg 